\title{
Evaluation of load balancing algorithms on overlappiing wireless accesspoints
}

\author{
Marion Olubunmi Adebiyi ${ }^{1}$, Egbe Egbe Adeka ${ }^{2}$, Florence A. Oladeji ${ }^{3}$, Roseline Oluwaseun \\ Ogundokun $^{4}$, Micheal Olaolu Arowolo ${ }^{5}$, Ayodele Ariyo Adebiyi ${ }^{6}$ \\ ${ }^{1,4,5,6}$ Department of Computer Science, Landmark University Omu Aran, Nigeria \\ ${ }^{2}$ Department of Computer and Information Science, Covenant University Ota, Nigeria \\ ${ }^{3}$ Department of Computer Science, University of Lagos, Nigeria
}

\begin{tabular}{l}
\hline \hline Article Info \\
\hline Article history: \\
Received Jul 25, 2020 \\
Revised Sep 27, 2020 \\
Accepted Oct 13, 2020 \\
\hline Keywords: \\
Load balancing \\
Overlapping \\
Round robin technique \\
Weighted round robin \\
technique \\
Wireless access point
\end{tabular}

Corresponding Author:

Roseline Oluwaseun Ogundokun

Department of Computer Science

Landmark University Omu Aran

Kwara State, Nigeria

Email: ogundokun.roseline@1mu.edu.ng

\begin{abstract}
Wireless networks came into the computing world replacing the costlier and more complex wired method of connecting numerous equipment in the same or different location via the use of cables. It provides the user devices a connection to one another and the greater internet via connections to access points. Generally, 802.11 access point products follow a default strongest signal first approach in selecting user devices or nodes to connect to the access point or overlapping access points. This standard does not make provisions for even distribution of load and hence the quality of service and the throughput in areas of congestion would be reduced. This article brings forward two algorithms used in load balancing and they include round-robin technique and the weighted round-robin technique to be used in the simulation of the distribution of the load amongst the access points with the results collated and compared to clearly show which algorithm is best suited to be used as a standard for access point load distribution.
\end{abstract}

This is an open access article under the CC BY-SA license.

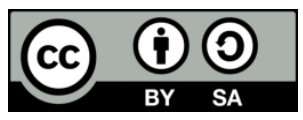

\section{INTRODUCTION}

Wireless networking is a method by which households, telecommunications networks and enterprise (business) facilities prevent the expensive process of installing cables in a building or connecting separate infrastructure sites [1-10]. Wireless mobile devices are becoming more and more ubiquitous and popular. Analysing [11-15] wireless networks formed over these devices are becoming an important field of research. The wireless network provides user connection to one another and the greater internet via connection to the access point within the coverage area. The users have the advantage of greater mobility within the area of the network coverage. When a device tries to connect to the network the following takes place as shown in Figure 1.

Hence the device would be connected to the network via the access point. A WLAN makes provision for several Access Points makes available service to clients in an individual topographical region $[16,17]$. Clients pick entry outlets centered on the wave power indicator (RSSI) provided the best. Therefore, while multiple APs can offer service to a congested area if clients are grouped, they appear to be linked to a similar AP. The less bandwidth they receive, the extra clients that are coupled to a distinct AP [18, 19]. For example, in the simple scenario shown below, all users are linked to AP B because each user has the highest 
signal strength. The users above are clustered in the coverage region of entry outlet B and are therefore connected to access point B with the strongest signal as display in Figure 2. Several factors bring about the congregation of users in a specific on a network these may include the availability of electric sockets for charging their devices, the availability of chairs for the users to sit and also the proximity of the access points to sources of entertainment or refreshment such as eateries [20-25]. Studying human mobility has become a subject of interest among the large community of researchers in the last decade, primarily because of its effect on so many different theoretical and application research [26-30].

This paper is therefore aimed at stimulating the effect of two scheduling algorithms in balancing the load on the network access point. We would be using the weighted round-robin technique in balancing the load on the network.
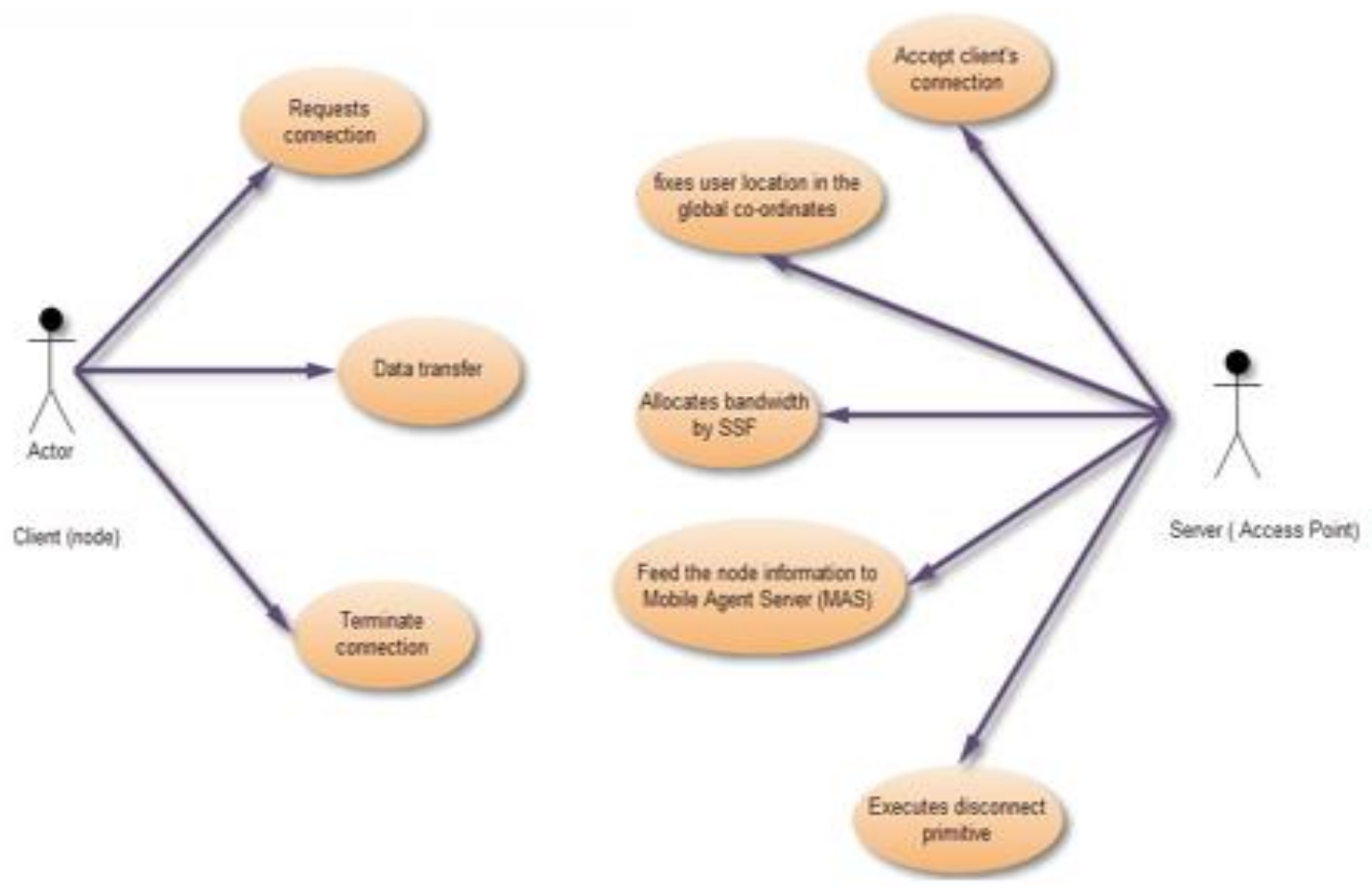

Figure 1. The connection process of a client to an access point

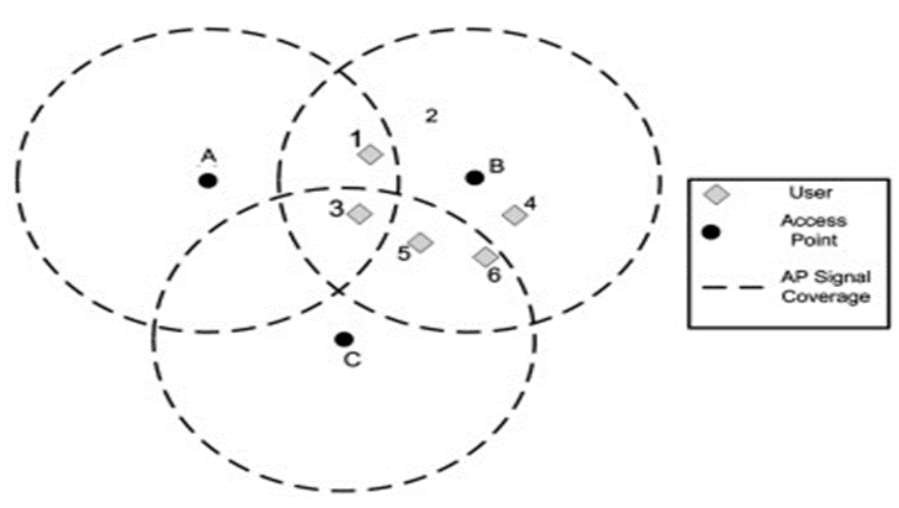

Figure 2. Users clustering in the coverage area of an access point

Weighted Round Robin Queuing Algorithm (WRR) queuing first classifies packets (e.g. instantaneous, collaborative, and file transmission) and then assigns them to a queue committed to serving each class. In the round-robin order, the queue is serviced. Contrary to strict PQ and FQ, there are no empty queues as shown in Figure 3. 


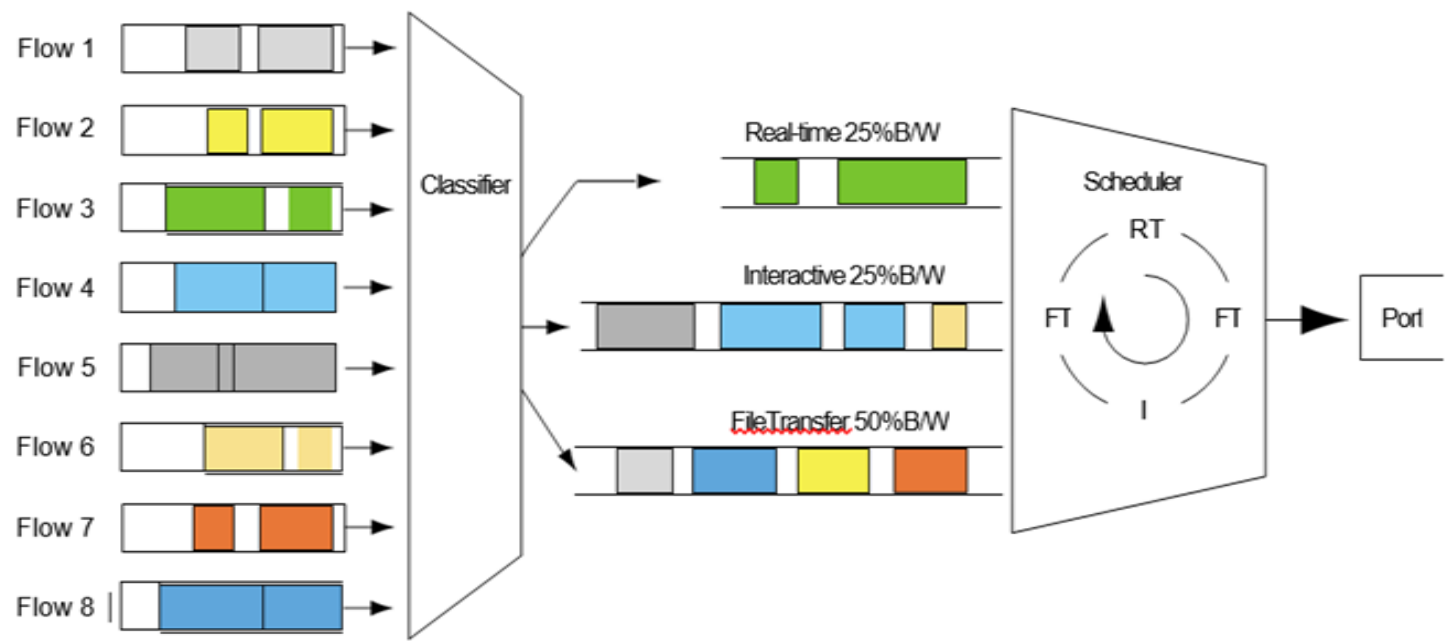

Figure 3. Diagram showing WRR scheduling

WRR queuing enables the allocation of various bandwidth volumes to different service groups either:

a) Permitting greater-bandwidth queues to dispatch extra packet every time they visit during a service round, or

b) Permitting every queue to dispatch just one packet every time they visit, thereby visiting numerous greater-bandwidth queues in a distinct service round.

$25 \%$ of the output port bandwidth is apportioned to the real-time traffic queue, and $25 \%$ of the interactive traffic queue is allocated to control the number of network resources apportioned to every service class:

a) The amount of delay faced by packets in a given queue is determined by a combination of the rate at which packets are placed in the output port bandwidth and the file transfer traffic queue assigned to $50 \%$ of the output port bandwidth. WRR queuing meets this weighted bandwidth allocation twice during access to the file transfer queue for each service.

b) The queue, the queue size, the quantity of traffic withdrawn from the queue in each service round and the number of other service groups (queues) in the output port.

c) The quantity of jitter experienced by the queue packets depends on the variability of the queue delay, the variability of the delay in all other queues and the variability of the round service duration.

A combination of the rate at which the packets are put in the queue, the size of the queue, the aggressiveness of the RED profiles designed for the queue, and the amount of traffic withdrawn from the queue at each service point determines the amount of packet loss experienced by each queue. You can handle the fill rate by conditioning the traffic at some stage in the upstream network.

\section{RESEARCH METHOD}

This section entails the methodology used for this paper and a brief description of the network simulator 2 and its components on a Linux operating system platform. The main purpose of this simulator is to simulate local area networks and wide area networks. The network simulator (version 2) is a script interpreter written in $\mathrm{OTcl}$ and $\mathrm{C}++$ that contains a simulation event scheduler and a simulation library as some of its major components. The user writes an OTcl script to build and run an event scheduler simulation network, build up the network topology by using the network objects as well as the plumbing functions of the library, instructing traffic sources on when to start and when to finish transmitting packets via the event scheduler. The term "plumbing" is used to set up a network, since setting up a network would plumb possible data paths between network objects by setting an object's "neighbor" point to an appropriate object's address.

Another component of the network simulator is the event scheduler and this is shown in Figure 4. In the event queue scheduled for the current time, the evet scheduler keeps the simulation time record filing all events. An event is a packet ID that is unique to a packet with a scheduled time and also an entity that manages the event. The load balancer: The load balancer is a major component which is at the core of the network simulator and it is responsible for the distribution of incoming traffic request and this is done by balancing application request across multiple servers. It improves the overall application responsiveness and availability. 


\section{RESULTS AND DISCUSSION}

\subsection{Simulation scenarios}

During the simulation, two traffic scenarios were considered. This made it possible to study the behavior of the schedulers under the same and different packet size distributions. The implemented scheduling algorithms simulated are strict weighted round-robin as in Figure 4. Figure 5 and 6 shows the Nam (Network Animator) and the Network Topology to be carried out.

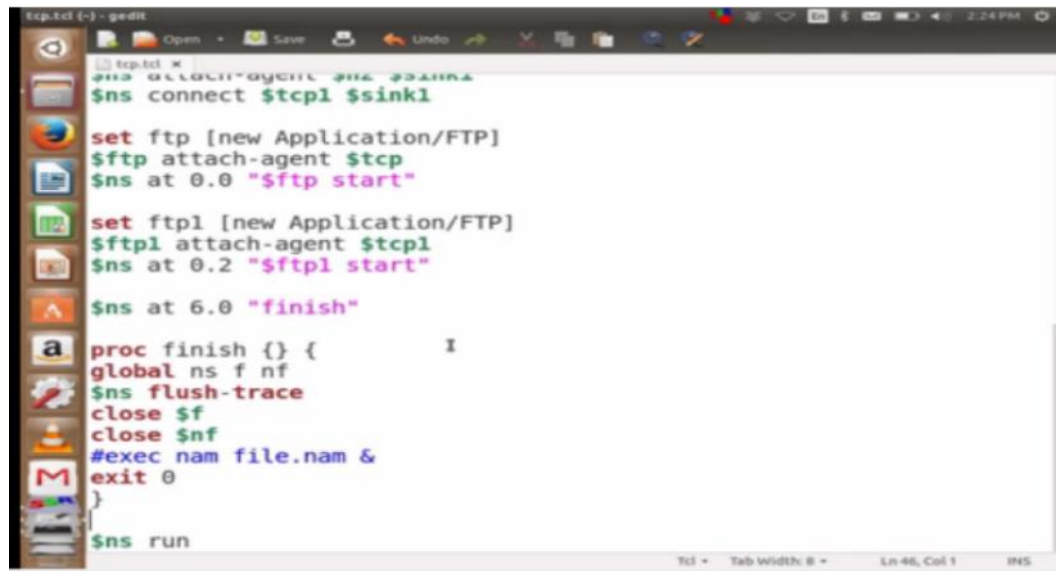

Figure 4. Otcl script to be ran by the network simulator 2

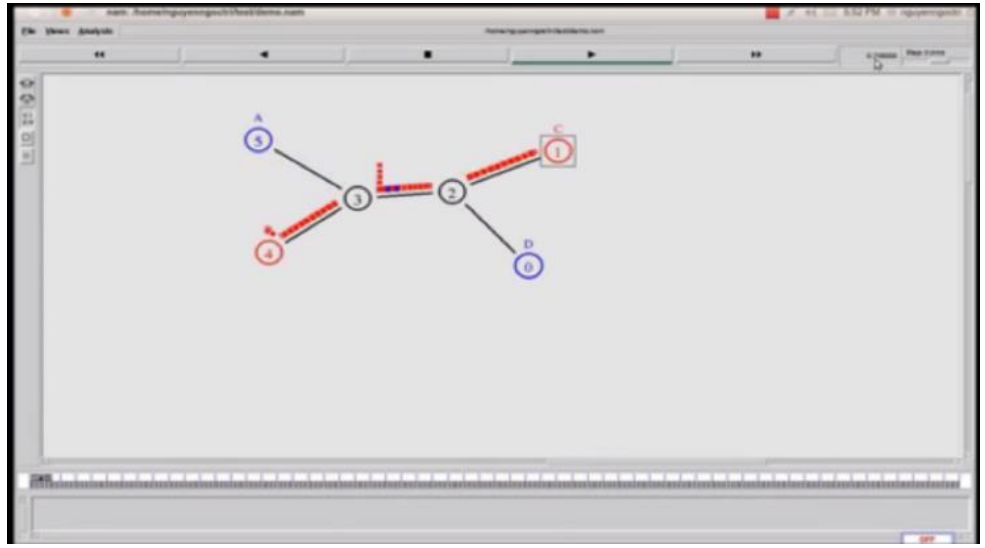

Figure 5. Nam (network animator)

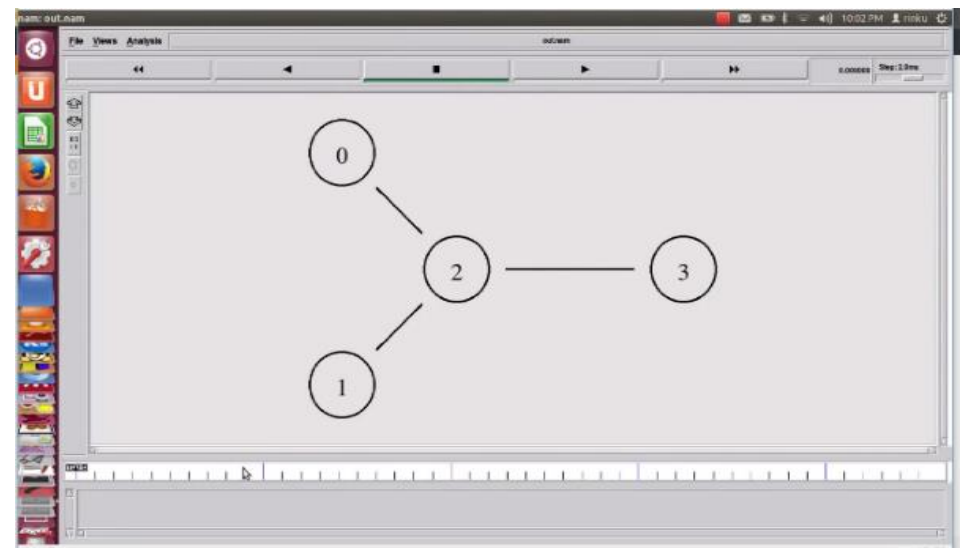

Figure 6. Network topology 
In the course of the programming and simulation, movement of packets in and out of core router 2 (c2 to e3) was traced and the scheduling processes after every 30seconds were recorded. Shows sample packet statistics from ns 2. Relevant fields are field 1 which indicates packet status (+ for enqueue, - for dequeue and $\mathrm{r}$ for receive), field 2 which shows time, field 5 that indicates the type of traffic (TCP, paroo, expoo or CBR) and field 12 for packet's unique identification. A packet may be enqueued, dequeued at a router or received at the destination as shown in Figure 7. Table 1 and 2 showing the total number of packets transferred after been ran for some time. Table 3 and 4 shows the total number of packets transferred after been ran for some time as well. The total number of loss rate from each of the three tables is as shown in the Table 5 to 9.

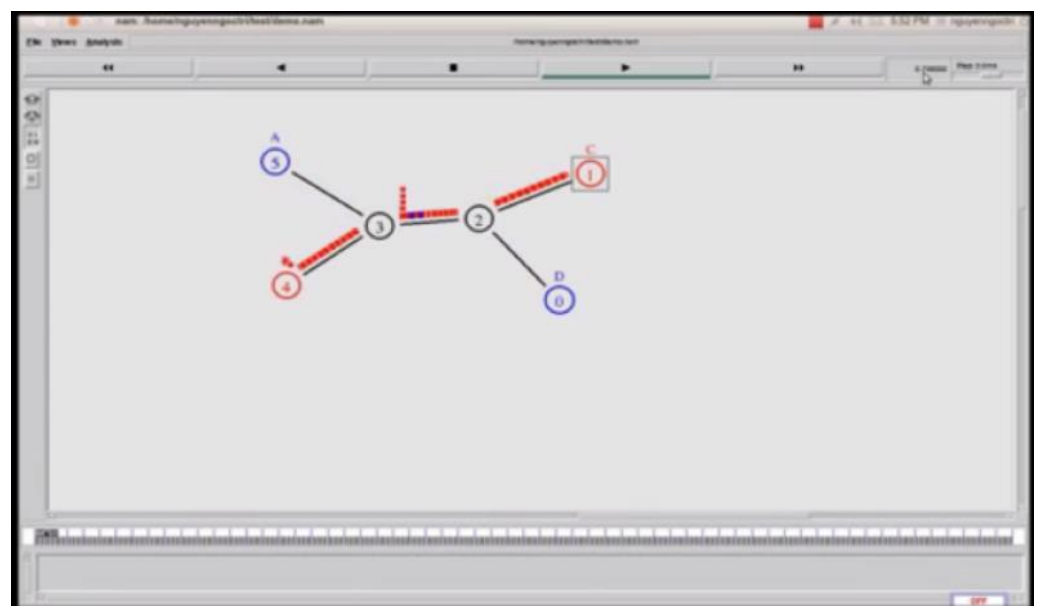

Figure 7. Network animator (nam) showing packets move to and from

Table 1. Total number of packets transferred

\begin{tabular}{ccccc}
\hline DSCP & TOTPKTS & TXTPKTS & LDROP & EDROP \\
\hline ALL & 79989 & 53782 & 20475 & 5732 \\
10 & 8758 & 8710 & 48 & 0 \\
11 & 26236 & 8804 & 15754 & 1678 \\
20 & 11258 & 11258 & 0 & 0 \\
21 & 33737 & 25010 & 4673 & 4054 \\
\hline
\end{tabular}

Table 3. Total number of packets transferred

\begin{tabular}{ccccc}
\hline DSCP & TOTPKTS & TXTPKTS & LDROP & EDROP \\
\hline ALL & 124989 & 81906 & 33633 & 9450 \\
10 & 14383 & 14335 & 48 & 0 \\
11 & 43111 & 14431 & 25924 & 2756 \\
20 & 16883 & 16883 & 0 & 0 \\
21 & 50612 & 36257 & 7661 & 6694 \\
\hline
\end{tabular}

Table 2. Total number of packets transferred

\begin{tabular}{ccccc}
\hline DSCP & TOTPKTS & TXTPKTS & LDROP & EDROP \\
\hline ALL & 124989 & 81906 & 33633 & 9450 \\
10 & 14383 & 14335 & 48 & 0 \\
11 & 43111 & 14431 & 25924 & 2756 \\
20 & 16883 & 16883 & 0 & 0 \\
21 & 50612 & 36257 & 7661 & 6694 \\
\hline
\end{tabular}

Table 4. Total number of packets transferred

\begin{tabular}{ccccc}
\hline DSCP & TOTPKTS & TXTPKTS & LDROP & EDROP \\
\hline ALL & 169989 & 110030 & 46806 & 13153 \\
10 & 20008 & 19960 & 48 & 0 \\
11 & 59986 & 20055 & 36048 & 3883 \\
20 & 22508 & 22508 & 0 & 0 \\
21 & 67487 & 47507 & 10710 & 9270 \\
\hline
\end{tabular}

Table 5. Table showing the total numbers of loss rate of the simulation

\begin{tabular}{ccccc}
\hline DSCP & TOTPKTS & TXTPKTS & LDROP & EDROP \\
\hline ALL & 34989 & 25655 & 7405 & 1929 \\
10 & 3133 & 3133 & 0 & 0 \\
11 & 9361 & 6428 & 1624 & 1309 \\
20 & 3633 & 5482 & 151 & 0 \\
21 & 16862 & 10612 & 5637 & 620 \\
\hline
\end{tabular}

Table 6. Total numbers of loss rate of the simulation

\begin{tabular}{ccccc}
\hline DSCP & TOTPKTS & TXTPKTS & LDROP & EDROP \\
\hline ALL & 45000 & 28123 & 13151 & 3726 \\
10 & 5625 & 5625 & 0 & 0 \\
11 & 16875 & 5623 & 10178 & 1074 \\
20 & 5625 & 5625 & 0 & 0 \\
21 & 16875 & 11250 & 2973 & 2652 \\
\hline
\end{tabular}

Table 7. Total numbers of loss rate of the simulation

\begin{tabular}{ccccc}
\hline DSCP & TOTPKTS & TXTPKTS & LDROP & EDROP \\
\hline ALL & 45000 & 28124 & 13158 & 3718 \\
10 & 5625 & 5625 & 0 & 0 \\
11 & 16875 & 5627 & 10170 & 1078 \\
20 & 5625 & 5625 & 0 & 0 \\
21 & 16875 & 11247 & 2988 & 2640 \\
\hline
\end{tabular}

Evaluation of load balancing algorithms on overlappiing wireless accesspoints (Marion Olubunmi Adebiyi) 
Table 8. Total numbers of loss rate of the simulation

\begin{tabular}{ccccc}
\hline DSCP & TOTPKTS & TXTPKTS & LDROP & EDROP \\
\hline ALL & 45000 & 28124 & 13173 & 3703 \\
10 & 5625 & 5625 & 0 & 0 \\
11 & 16875 & 5624 & 10124 & 1127 \\
20 & 5625 & 5625 & 0 & 0 \\
21 & 16875 & 11250 & 3049 & 2576 \\
\hline
\end{tabular}

Table 9. Total numbers of loss rate of the simulation

\begin{tabular}{ccccc}
\hline & FIRST & SECOND & THIRD & FOURTH \\
\hline ALL & 25655 & 28123 & 28124 & 28124 \\
Q10 & 3133 & 5625 & 5625 & 5625 \\
Q11 & 6428 & 5623 & 5627 & 5624 \\
Q20 & 5482 & 5625 & 5625 & 5625 \\
Q21 & 10612 & 11250 & 11247 & 11250 \\
\hline
\end{tabular}

The Table 10 shows the total number of throughput with a graphical view of it in Figure 8 . Table 10 shows the fairness of the developed system. The summary of the results gotten from the simulation process were also given below so as so make the process easier to understand so the summary of this whole process is given in Table 11.

Table 10. Fairness

\begin{tabular}{cccc}
\hline FAIRNESS & \multicolumn{1}{c}{$\mathrm{X}$} & $\mathrm{X}^{2}$ \\
\hline & SOURCE1 & 40015 & 1601200225 \\
ADDITION & SOURCE2 & 70015 & 4902100225 \\
SQUAREADD & 110030 & 12106600900 & \\
& & & 6503300450 \\
FAIRNES & & 0.930804366 & 93.08043657 \\
\hline
\end{tabular}

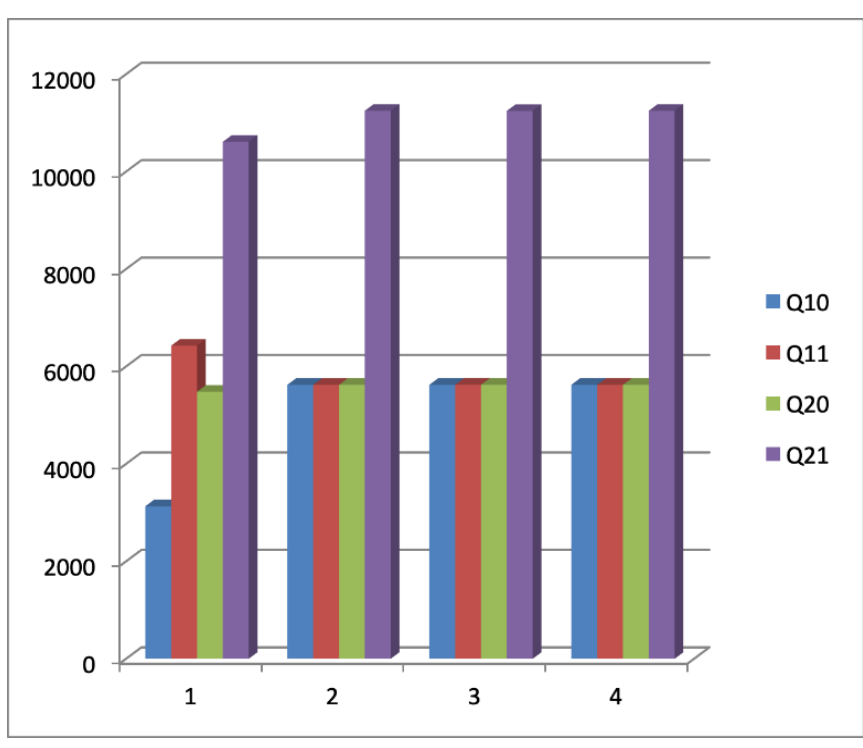

Table 11. Summary of simulation process

\begin{tabular}{cc}
\hline SUMMARY OF THE SIMULATION PROCESS \\
\hline LOSS RsTE & 35.27228232 \\
FAIRNESS & 93.08043657 \\
DELAY & 0.069675291 \\
EFFICIENCY & 64.72771768 \\
\hline
\end{tabular}

Figure 8. Total number of throughputs

\section{CONCLUSION}

The article brought forward two algorithms used in load balancing and they are round-robin technique and the weighted round-robin technique. The two techniques were used in the simulation of the distribution of the load amongst the access points and the results got were collated and compared to clearly show which algorithm is best suited to be used as a standard for access point load distribution.

\section{ACKNOWLEDGEMENTS}

We greatly appreciate the opportunity provided by Covenant University to conduct this research and this research is fully sponsored by Landmark University Centre for Research and Development, Landmark University, Omu Aran, Nigeria. 


\section{REFERENCES}

[1] J. Mo and J. Walrand, "Fair end-to-end window-based congestion control," IEEE/ACM Trans. Networking, vol. 8, no. 5, pp. 556-567, 2000.

[2] S. P. Boyd and L. Vandenberghe, Convex Optimization, Cambridge University Press, 2004.

[3] M. Katevenis, S. Sidiropoulos, and C. Courcoubetis, "Weighted round robin cell multiplexing in a general-purpose ATM switch chip," IEEE journal on selected areas in communications, vol. 9, no. 8, pp. 1265-1279, 1991.

[4] A. Charny, "An algorithm for rate allocation in a packet-switching network with feedback," Master's thesis, Mass. Inst. Technol., Cambridge, MA, 1994.

[5] "Overview of Wireless Communications," Cambridge.org (accessed Feb. 8, 2008).

[6] Semeria C., "Supporting differentiated service classes: queue scheduling Disciplines," juniper networks, 2001.

[7] J. Chung and M. Claypool, "NS by example," Worcester Polytechnic Institute Computer Science, http://nile.wpi.edu/NS/. 2002.

[8] D. Chiu and R. Jain, "Analysis of the increase and decrease algorithms for congestion avoidance in computer networks," Computer Networks ISDN Syst., vol. 17, pp. 1-14, 1989.

[9] Manish and R. K. Cheema, "A Min-Max approach to perform load balancing in distributed network," 2012 Second International Conference on Advanced Computing \& Communication Technologies, Rohtak, Haryana, pp. 200-203, 2012.

[10] Y. Bejerano and S. J. Han, "Cell Breathing Techniques for Load Balancing in Wireless LANs," Proc. IEEE INFOCOM, 2006.

[11] I. Tinnirello and G. Bianchi, "A Simulation Study of Load Balancing Algorithms in Cellular Packet Networks," MSWIM '01: Proceedings of the 4th ACM international workshop on Modeling, analysis and simulation of wireless and mobile systems, pp. 73-78, 2001.

[12] J. B. Awotunde, R. O. Ogundokun, F. E. Ayo, G. I. Ajamu, E. A. Adeniyi, E. O. Ogundokun, "Social Media Acceptance and Use Among University Students for Learning Purpose Using UTAUT Model Advances" in Intelligent Systems and Computing, pp. 91-102, 2020.

[13] V. Priya, C. S. Kumar, and R. Kannan, "Resource scheduling algorithm with load balancing for cloud service provisioning," Applied Soft Computing, vol. 76, pp. 416-424, 2019.

[14] M. Adebiyi, F. Oladeji, S. Onyido, D. Ori, R. Ogundokun, E. Adeniyi, and O. Okesola, "A 3-D Model of an Institutional Location Navigation System (Naviloc)," A Case Study of Covenant University. International Journal of Civil Engineering and Technology, vol. 10, no. 1, pp. 746-756, 2019.

[15] R. O. Ogundokun, et al., "Evaluation of the scholastic performance of students in 12 programs from a private university in the south-west geopolitical zone in Nigeria," F1000Research, vol. 8, 2019.

[16] M. Anedda, G. M. Muntean, and M. Murroni, "Adaptive real-time multi-user access network selection algorithm for load-balancing over heterogeneous wireless networks," in 2016 IEEE International Symposium on Broadband Multimedia Systems and Broadcasting (BMSB), pp. 1-4, 2016.

[17] G. Scaglione, U.S. Patent 8,339,951, 2012.

[18] M. Adhikari, S. Nandy, and T. Amgoth, "Meta heuristic-based task deployment mechanism for load balancing in IaaS cloud," Journal of Network and Computer Applications, vol. 128, pp. 64-77, 2019.

[19] K. Mishra and S. Majhi, "A State-of-Art on Cloud Load Balancing Algorithms," International Journal of Computing and Digital Systems, vol. 9, no. 2, pp. 201-220, 2020.

[20] M. Katyal and A. Mishra, "A comparative study of load balancing algorithms in cloud computing environment," arXiv preprint arXiv: 1403.6918, 2014.

[21] S. Ray and A. De Sarkar, "Execution analysis of load balancing algorithms in cloud computing environment," International Journal on Cloud Computing: Services and Architecture (IJCCSA), vol. 2, no. 5, pp. 1-13, 2012.

[22] M. Lin, Z. Liu, A. Wierman, and L. L. Andrew, "Online algorithms for geographical load balancing," in 2012 international green computing conference (IGCC), pp. 1-10, 2012.

[23] S. Aslam and M. A. Shah, "Load balancing algorithms in cloud computing: A survey of modern techniques," in 2015 National software engineering conference (NSEC), pp. 30-35, 2015.

[24] M. Salhani and M. Liinaharja, "Load Balancing in UDN Networks by Migration Mechanism with Respect to the D2D Communications and E2E Delay," JCM, vol. 14, no. 4, pp. 2490-260, 2019.

[25] M. Grayson and K. Shatzkamer, U.S. Patent 9,559,866, 2017.

[26] H. Liu and T. M. Pang, U.S. Patent 9,867,083, 2018.

[27] C. J. Napitupulu, P. Sihombing, and S. Suherman, "Optimizing the 802.11 hotspot performances by using load and resource balancing method," in IOP Conference Series: Materials Science and Engineering, vol. 420, no. 1, p. $012128,2018$.

[28] R. Abbasi, S. M. M. Gilani, A. Kabir, Q. Nawaz, and M. S. Riaz, "Load Balancing of SDN-enabled Wireless Network: Challenges, Technique and Evaluation," Journal of Information Communication Technologies and Robotic Applications, pp. 80-92, 2019.

[29] E. F. Aza and J. P. Urrea, "Implementation of Round-Robin load balancing scheme in a wireless software defined network," in 2019 IEEE Colombian Conference on Communications and Computing (COLCOM), pp. 1-6, 2019.

[30] S. M. M. Gilani, T. Hong, G. Zhao, C. Xu, and M. A. Abbas, "An Empirical Throughput Analysis of Multimedia Applications with OpenFlow-based Dynamic Load Balancing Approach in WLAN," Journal of Internet Technology, vol. 20, no. 1, pp. 237-246, 2019. 


\section{BIOGRAPHIES OF AUTHORS}

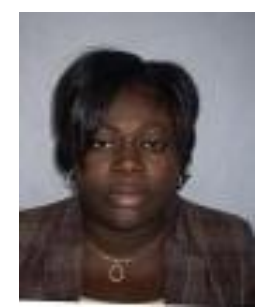

Marion Olubunmi Adebiyi is a Senior Lecturer at Covenant University Ota Ogun State in the Department of Computer \& Information Sciences. She had obtained NCE (Mathematics/ Physics, 1995), B. Sc. (Computer Science, 2000), M. Sc. and P. hD also in Computer Science (Bioinformatics), 2008 and 2014 consecutively. Her research interests include Anti-malaria drugs/ insecticide resistance mechanism discovery, organism's inter-pathways analysis, developing pipeline for high throughput data analysis and 3D protein structure and function prediction. She has published several articles in learned journals and chapters in books. She is a member of Computer Professionals (CPN), Nigeria Computer Society (NCS) and Institute of Electrical and Electronics Engineers (MIEEE) and International / African Society for Computational Biology/ and Bioinformatics (ISCB/ASBCB).

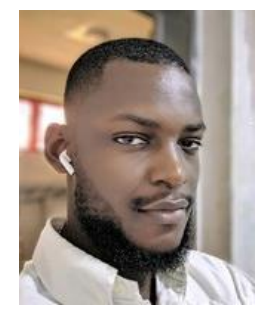

Egbe Egbe Adeka is an experienced Finance officer with a demonstrated history of working in the banking industry. Skilled in Management and Software Development. Strong finance professional with a Bachelor's degree focused in Computer Science from Covenant University.

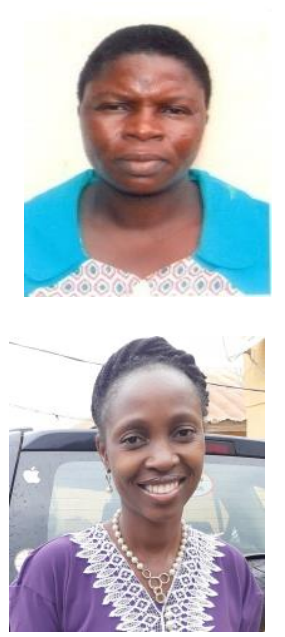

Dr. F. A. Oladeji is an adjunct lecturer in the Department of Computer Science and Mathematics. She has a BSc., M.Sc., and Ph.D. degree in Computer Science. Her areas of research interest include computer networks, security systems, and intelligent systems.

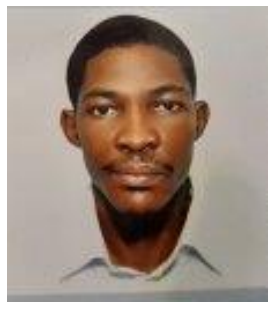

Roseline Oluwaseun Ogundokun is a Lecturer at the Department of Computer Science, College of Pure and Applied Sciences, Landmark University, Omu Aran, Kwara State, Nigeria, she holds Bachelor of Science in Management Information System from Covenant University, Ota; Master of Science in Computer Science from the University of Ilorin, Ilorin; Post Graduate Diploma in Education (PGDE) from the National Teachers' Institute (NTI), Kaduna and; currently a PhD student in the Department of Computer Science, University of Ilorin, Ilorin. Her research interests include Steganography and Cryptography, Information Security, Artificial Intelligence, Data Mining, Information Science and Human Computer Interaction.

Micheal Olaolu Arowolo is an Assistant Lecturer at Landmark University Omu Aran. He is a researcher, lecturer, developer and Oracle certified expert. He is a member of IAENG and PMP. His research area of interest re Bioinformatics, Machine learning, Big Data, Data Science and Computational Biology.

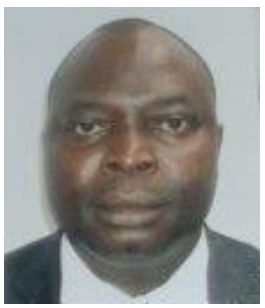

Ayodele Ariyo Adebiyi is a Prof of Computer Science at Landmark University Omu Aran. He graduated from University of Ilorin with a B.Sc. degree in Computer Science. He holds Master of Business Administration from University of Ilorin, 2000. He attended Covenant University both for his M.Sc. in Management Information System (2006) and a Ph.D. (2012) in the same field. He has published several articles in learned journals and chapters of books. He is a member of Computer Professionals (CPN), Nigeria Computer Society (NCS) and Institute of Electrical and Electronics Engineers (MIEEE) 